\title{
Varenicline and Cytisine Diminish the Dysphoric-Like State Associated with Spontaneous Nicotine Withdrawal in Rats
}

\author{
Moe Igari', Jon C Alexander', Yue Ji', Xiaoli Qi', Roger L Papke² and Adrie W Bruijnzeel*,' \\ 'Department of Psychiatry, McKnight Brain Institute, University of Florida, Gainesville, FL, USA; ${ }^{2}$ Department of Pharmacology and Therapeutics, \\ University of Florida, Gainesville, FL, USA
}

\begin{abstract}
Tobacco addiction is characterized by a negative mood state upon smoking cessation and relapse after periods of abstinence. Clinical studies indicate that negative mood states lead to craving and relapse. The partial $\alpha 4 / \alpha 6 / \beta 2 *$ nicotinic acetylcholine receptor (nAChR) agonists varenicline and cytisine are widely used as smoking cessation treatments. Varenicline has been approved in the United States for smoking cessation and cytisine is used in Eastern European countries. Despite the widespread use of these compounds, very little is known about their effects on mood states. These studies investigated the effects of varenicline, cytisine, and the cytisine-derivative 3-(pyridin-3'-yl)-cytisine (3-pyr-Cyt) on brain reward function in nicotine-naive and nicotine-withdrawing rats. The cytisine-derivative 3 -pyr-Cyt is a very weak $\alpha 4 \beta 2^{*}$ nAChR partial agonist and like cytisine and varenicline has antidepressant-like effects in animal models. The intracranial self-stimulation (ICSS) procedure was used to investigate the effects of these compounds on brain reward function. Elevations in ICSS thresholds reflect a dysphoric state and a lowering of thresholds is indicative of a potentiation of brain reward function. It was shown that acute administration of nicotine and varenicline lowered ICSS thresholds. Acute administration of cytisine or 3-pyr-Cyt did not affect ICSS thresholds. Discontinuation of chronic, I 4 days, nicotine administration led to elevations in ICSS thresholds that lasted for about 2 days. Varenicline and cytisine, but not 3-pyr-Cyt, diminished the nicotine withdrawal-induced elevations in ICSS thresholds. In conclusion, these studies indicate that varenicline and cytisine diminish the dysphoric-like state associated with nicotine withdrawal and may thereby prevent relapse to smoking in humans.

Neuropsychopharmacology (2014) 39, 445-455; doi: 10.1038/npp.2013.216; published online 25 September 2013
\end{abstract}

Keywords: nicotine; varenicline; cytisine; withdrawal; ICSS; rats

\section{INTRODUCTION}

Tobacco products are highly addictive and smoking cessation leads to dysphoria, craving, and impaired cognitive function (American Psychiatric Association, 2000; Bruijnzeel, 2012). Extensive evidence indicates that nicotine is the main psychoactive component of tobacco that leads to addiction (Stolerman and Jarvis, 1995). Nicotine mediates its psychoactive effects by stimulating nicotinic acetylcholine receptors (nAChRs) in the brain. The nAChRs are pentameric ligand-gated ion channels. In the mammalian brain, the heteromeric nAChRs consist of $\alpha 2-6$ and $\beta 2-4$ subunits and the homomeric nAChRs consist of $\alpha 7$ subunits (Dani and Bertrand, 2007; Leslie et al, 2013). Nicotine mediates its rewarding effects at least partly by activating $\alpha 4 / \alpha 6 / \beta 2^{*}, \alpha 3 \beta 4^{*}$, and $\alpha 7 \mathrm{nAChRs} \mathrm{(Liu} \mathrm{et} \mathrm{al,}$ 2012; Picciotto and Kenny, 2013; Jackson et al, 2013; Toll et al, 2012; Markou and Paterson, 2001). Cessation of nicotine administration leads to negative affective (dyspho-

\footnotetext{
*Correspondence: Dr AW Bruijnzeel, Department of Psychiatry, McKnight Brain Institute, University of Florida, II49 Newell Drive, Gainesville, FL 326।I, USA, Tel: + I 352294 4931, Fax: + I 35239282 17, E-mail: awbruijn@ufl.edu

Received 27 June 2013; revised 7 August 2013; accepted II August 2013; accepted article preview online 21 August 2013
}

ric- and anxiety-like behavior) and somatic withdrawal signs (Epping-Jordan et al, 1998). Clinical and preclinical studies suggest that relapse to smoking is mainly due to craving and negative affective withdrawal signs (Bruijnzeel, 2012; Koob and Volkow, 2010). There is extensive evidence for a role of $\alpha 4 \beta 2^{\star}$ nAChRs in dysphoric- and anxiety-like behavior associated with nicotine withdrawal (Picciotto and Kenny, 2013; Changeux, 2010).

During the past decade, a great deal of progress has been made towards the development of treatments for tobacco addiction. Smoking cessation treatments target non-cholinergic receptors (eg, clonidine), a combination of cholinergic and non-cholinergic receptors (eg, bupropion), or only cholinergic receptors (eg, varenicline and cytisine) (Gourlay et al, 2004; Slemmer et al, 2000; Jorenby et al, 2006). In the present studies, we evaluated the effects of three structurally related cholinergic receptor agonists (cytisine, varenicline, and 3-(pyridin-3'-yl)-cytisine (3-pyr-Cyt)) on nicotine withdrawal in rats. Both varenicline and 3-pyr-Cyt were developed by modifying the chemical structure of cytisine. Varenicline was discovered while searching for more potent and efficacious $\alpha 4 \beta 2^{*}$ nAChR partial agonists and 3-pyr-Cyt was discovered during a search for more selective $\alpha 4 \beta 2^{*}$ nAChR partial agonists (Coe et al, 2005; Mineur et al, 2009). Cytisine has been used as a smoking cessation aid in Eastern European countries since the 1960s (Etter, 2006; 
West et al, 2011). Cytisine is a partial agonist at $\alpha 4 \beta 2^{\star}$ and $\alpha 6 \beta 2^{\star}$ nAChRs and a full agonist at $\alpha 3 \beta 4^{*}$ and $\alpha 7 \mathrm{nAChRs}$ (Salminen et al, 2004; Grady et al, 2010). The cytisine derivative varenicline is an US FDA-approved smoking cessation treatment and activates the same nAChRs as cytisine (Grady et al, 2010; Mihalak et al, 2006). Cytisine and varenicline have a similar efficacy at $\alpha 4 \beta 2^{\star}, \alpha 3 \beta 4^{*}$, and $\alpha 7$ rodent nAChRs, but cytisine is more efficacious at $\alpha 6 \beta 2^{*}$ nAChRs (Grady et al, 2010; Salminen et al, 2004).

Some preclinical studies suggest that cytisine has rewarding effects. Cytisine is self-administered by mice, induces conditioned place preference (CPP), and repeated administration of cytisine leads to a sensitized locomotor response in rats (Museo and Wise, 1994a, b;Rasmussen and Swedberg, 1998). Drug discrimination studies indicate that cytisine partially generalizes (ie, substitutes) for nicotine (Stolerman et al, 1984; LeSage et al, 2009). Few studies have investigated the rewarding effects of varenicline. One study showed that low, but not high, doses of varenicline induce a leftward shift in a rate-frequency curve-shift intracranial self-stimulation (ICSS) procedure, which suggests that varenicline has rewarding effects (Spiller et al, 2009). In contrast, varenicline does not induce CPP, which would suggest that varenicline does not have rewarding properties (Biala et al, 2010).

Despite the fact that cytisine and varenicline are widely used as treatments for smoking cessation, it has not been investigated if varenicline and cytisine diminish the dysphoria associated with nicotine withdrawal. The aim of these studies was to investigate the effects of cytisine and varenicline on brain reward function in nicotine-naive and nicotine-withdrawing rats by using a discrete-trial ICSS procedure. The acute administration of drugs of abuse lowers ICSS thresholds, which is indicative of a potentiation of brain reward function. In contrast, drug withdrawal leads to elevations in ICSS thresholds, which reflects a dysphoriclike state (Barr et al, 2002). In addition to the effects of cytisine and varenicline, the effects of the cytisine derivative 3 -pyr-Cyt on brain reward function was evaluated. This compound is a very weak partial agonist at $\alpha 4 \beta 2^{*}$ nAChRs and inhibits acetylcholine-mediated responses on $\alpha 4 \beta 2^{\star}$ nAChRs expressed in oocytes (Mineur et al, 2009; Papke et al, 2010). In contrast to varenicline and cytisine, 3-pyrCyt does not bind to $\alpha 3 \beta 4^{*}$ or $\alpha 7$ nAChRs and might therefore have a better side-effect profile (Mineur et al, 2009). Like varenicline and cytisine, 3-pyr-Cyt has antidepressant-like effects in a variety of mouse models (Mineur et al, 2009).

\section{MATERIALS AND METHODS}

\section{Subjects}

Male wistar rats (200-225 g; Charles River, Raleigh, NC) were used for the experiments. The animals were housed ( 2 per cage) in a temperature- and humidity-controlled vivarium and maintained on a 12 -h light-dark cycle (light off at 0800 hours). All experiments were conducted during the dark phase. All subjects were treated in accordance with the National Institute of Health guidelines regarding the principles of animal care. Animal facilities and experimental protocols were in accordance with the Association for the
Assessment and Accreditation of Laboratory Animal Care (AAALAC) and approved by the University of Florida Institutional Animal Care and Use Committee.

\section{Drugs}

Nicotine and mecamylamine were purchased from SigmaAldrich (St Louis, MO). Varenicline, cytisine, and 3-pyr-Cyt were purchased from Tocris (Ellisville, MO). All drugs were dissolved in sterile saline. The $\mathrm{pH}$ of the nicotine solution was adjusted to 7.0 immediately before the subcutaneous injections. The drug 3-pyr-Cyt was dissolved by heating the mixture to $40^{\circ} \mathrm{C}$. All drugs were injected (subcutaneously) in a volume of $1 \mathrm{ml} / \mathrm{kg}$ of body weight. Nicotine doses are expressed as free base and other drug doses are expressed as salt.

\section{Surgical Procedures}

The surgical procedures were conducted as described previously by our group (Bruijnzeel et al, 2009, 2012; Marcinkiewcz et al, 2009).

Electrode implantations. The rats were anesthetized with isoflurane and prepared with electrodes (Plastic One, Roanoke, $\mathrm{VA}$ ) in the medial forebrain bundle (anterior-posterior, $-0.5 \mathrm{~mm}$; medial lateral, $\pm 1.7 \mathrm{~mm}$; dorsal-ventral, $-8.3 \mathrm{~mm}$ from dura).

Osmotic minipump implantations and removal. Anesthetized rats were prepared with minipumps (28 days; Durect Corporation, Cupertino, CA) that were filled with either saline or nicotine. The nicotine concentration was adjusted for body weight and to deliver $3.16 \mathrm{mg} / \mathrm{kg}$ of nicotine base per day.

\section{ICSS Procedure}

Rats were trained on a modified discrete-trial ICSS procedure (Kornetsky and Esposito, 1979), as described previously (Markou and Koob, 1992; Bruijnzeel et al, 2007). The operant conditioning chambers were housed in soundattenuating chambers (Med Associates, Georgia, VT). The operant conditioning chambers had a response wheel centered on a sidewall and a photobeam detector recorded the rotations. Brain stimulation was delivered by constant current stimulators (Stimtek, Acton, MA). After the rats were trained, each test session provided an ICSS threshold and response latency. The ICSS threshold was defined as the midpoint between stimulation intensities that supported responding and current intensities that failed to support responding. The response latency was defined as the time interval between the beginning of the non-contingent stimulus and a positive response.

\section{Experimental Design}

Experiments 1.1-1.4: Acute effect of nicotine (1.1), varenicline (1.2), cytisine (1.3), and 3-pyr-Cyt (1.4) on brain reward function. Drug-naive rats were used for all experiments. Rats were prepared with electrodes and trained on the ICSS procedure. When the ICSS thresholds 
were stable ( $<10 \%$ variation over 5 -day period), the rats received nicotine $(0,0.03,0.1,0.3$, and $0.6 \mathrm{mg} / \mathrm{kg}, n=12)$, varenicline $(0,0.1,0.3,1$, and $3 \mathrm{mg} / \mathrm{kg}, n=9)$, cytisine $(0$, $0.1,0.3,1,3$, and $5 \mathrm{mg} / \mathrm{kg}, n=12)$, or 3-pyr-Cyt $(0,0.3,0.6$, and $0.9 \mathrm{mg} / \mathrm{kg}, n=13)$. Varenicline and 3 -pyr-Cyt were administrated $30 \mathrm{~min}$ before testing and cytisine and nicotine $15 \mathrm{~min}$ before testing. The drugs were administered according to a Latin-square design. One dose of cytisine $(5 \mathrm{mg} / \mathrm{kg})$ and one dose of varenicline $(0.1 \mathrm{mg} / \mathrm{kg})$ were added after the Latin-square to complete the dose-response curves. It was also investigated if the effects of varenicline on ICSS thresholds were mediated by the activation of nAChRs. Therefore, the nAChR antagonist mecamylamine $(3 \mathrm{mg} / \mathrm{kg})$ was injected $15 \mathrm{~min}$ before the administration of $0.3 \mathrm{mg} / \mathrm{kg}$ of varenicline. In all the experiments, the minimum time interval between the drug injections was at least $72 \mathrm{~h}$. All the tested drugs have short half-lives in rats (nicotine $t_{1 / 2}=1.3 \mathrm{~h}$; varenicline $t_{1 / 2}=4 \mathrm{~h}$; cytisine $t_{1 / 2}=1.5 \mathrm{~h}$; mecamylamine $t_{1 / 2}=1.2 \mathrm{~h}$ ) (Kyerematen et al, 1988; Rollema et al, 2010; Obach et al, 2006; Debruyne et al, 2003). The half-life of 3-pyr-Cyt has not been reported. However, in previous studies a wash-out period of $48 \mathrm{~h}$ ( $>72 \mathrm{~h}$ in the present study) was used between injections (Mineur et al, 2009).

Experiments 2.1-2.3: Effect of varenicline (2.1), cytisine (2.2), and 3-pyr-Cyt (2.3) on brain reward function in nicotine-withdrawing rats. The rats were trained on the ICSS procedure and when the ICSS thresholds were stable, the rats were prepared with nicotine or saline pumps. The minipumps were removed after 14 days. The ICSS thresholds were assessed 6, 12, 24, 36, 48, 72, 83, 96, 120, 144, and $168 \mathrm{~h}$ after minipump removal. Varenicline $(0.3 \mathrm{mg} / \mathrm{kg}$, subcutaneously; saline-pump/varenicline-injection (inj), $n=9$; nicotine-pump/varenicline-inj, $n=13$ ), 3-pyr-Cyt ( $0.3 \mathrm{mg} / \mathrm{kg}$, subcutaneously; saline-pump/3-pyr-Cyt-inj, $n=9$; nicotine-pump/3-pyr-Cyt-inj, $n=12$ ), or saline (saline-pump/saline-inj, $n=9 ;$ nicotine-pump/saline-inj, $n=14$ ) were injected $30 \mathrm{~min}$ before ICSS testing at the $12-72 \mathrm{~h}$ time points. Cytisine $(3 \mathrm{mg} / \mathrm{kg}$, subcutaneously; saline-pump/cytisine-inj, $n=10$; nicotine-pump/cytisineinj, $n=12$ ) was administrated 15 min before ICSS testing. The same saline-pump/saline-inj and nicotine-pump/salineinj groups served as control for Experiments 2.1-2.3. The ICSS thresholds were assessed for an additional 4 days after discontinuing varenicline, cytisine, or 3-pyr-Cyt administration.

\section{Statistical Analyses}

The ICSS parameters were expressed as a percentage of the 3-day baseline before the first drug injection (Exp. 1) or before pump removal (Exp. 2). For Experiment 1, one-way repeated-measures analyses of variance (ANOVA) were used to analyze the effects of nicotine, varenicline, cytisine, and 3-pyr-Cyt on ICSS parameters. When the ANOVAs revealed significant effects, then Newman-Keuls post hoc tests were conducted. For Experiment 2, paired $t$-tests were conducted to investigate the effect of chronic (14 days) administration of nicotine or saline on ICSS parameters (prepump implantation $v s$ prepump removal). Bonferroni corrected $t$-tests were conducted to compare ICSS para-
Table I Absolute Baseline ICSS Thresholds and Response Latencies Before First Drug Injection

\begin{tabular}{lrcc}
\hline Compound & $\boldsymbol{N}$ & Thresholds $(\boldsymbol{\mu A})$ & Latencies (s) \\
\hline Nicotine (Exp. I.I) & 12 & $91.1 \pm 4.9$ & $3.1 \pm 0.1$ \\
Varenicline (Exp. I.2) & 9 & $124.1 \pm 13.2$ & $3.4 \pm 0.1$ \\
Cytisine (Exp. I.3) & 12 & $126.8 \pm 8.4$ & $3.3 \pm 0.1$ \\
3-pyr-Cyt (Exp. I.4) & 13 & $102.1 \pm 5.4$ & $3.4 \pm 0.1$ \\
\hline
\end{tabular}

The baselines are averages of thresholds and latencies that were obtained on three consecutive days before the first drug injection.

meters between groups. Three-way ANOVAs (6-168 h time points) were conducted to investigate the effects of varenicline, cytisine, and 3-pyr-Cyt on spontaneous nicotine withdrawal with time as within-subjects factor and pump content and drug as between-subjects factors. To investigate the effects of the drugs on nicotine-withdrawing rats or control rats (12-72 h) additional two-way ANOVAs were conducted. Area under the curves (AUCs) were analyzed with a two-way ANOVA with pump content and drug as between-subjects factors. After the ANOVA, all the saline groups were compared with the saline-saline group and all nicotine groups to the nicotine-nicotine group by using the Dunnett's multiple comparison procedure (Dunnett, 1955). Statistical analyses were performed using IBM SPSS (version 21) for Windows software.

\section{RESULTS}

\section{Experiments 1.1-1.4: Effect of Nicotine, Varenicline, Cytisine, and 3-Pyr-Cyt on ICSS Thresholds}

The mean ( \pm SEM) absolute ICSS thresholds and response latencies (3-day averages) before the administration of nicotine, varenicline, cytisine, and 3-pyr-Cyt are reported in Table 1. Repeated administration of the drugs did not alter the pretest day ICSS thresholds or response latencies (data not shown).

Nicotine (Exp. 1.1). There was a main effect of nicotine on ICSS thresholds (F4,44 $=15.14, p<0.001$, Figure 1a) and response latencies $(\mathrm{F} 4,44=2.91, p<0.05$; Figure $1 \mathrm{~b})$. Post hoc analyses indicated that the effect of nicotine on ICSS thresholds is bidirectional, low doses of nicotine $(0.1$ and $0.3 \mathrm{mg} / \mathrm{kg}$ ) lowered ICSS thresholds and high doses of nicotine $(0.6 \mathrm{mg} / \mathrm{kg})$ elevated ICSS thresholds. In addition, nicotine $(0.3 \mathrm{mg} / \mathrm{kg})$ decreased the response latencies, which is indicative of a stimulant-like effect.

Varenicline (Exp. 1.2). The ANOVA analysis indicated that there was a main effect of varenicline on ICSS thresholds $(\mathrm{F} 4,32=3.60, p<0.05$; Figure $2 \mathrm{a})$ and response latencies $(\mathrm{F} 4,32=3.38, p<0.05$; Figure $2 \mathrm{~b})$. The post hoc comparisons revealed that low doses of varenicline lowered ICSS thresholds $(0.1,0.3$, and $1 \mathrm{mg} / \mathrm{kg})$ and decreased the response latencies $(0.1$ and $0.3 \mathrm{mg} / \mathrm{kg})$. Pretreatment with the $\mathrm{nAChR}$ antagonist mecamylamine prevented the varenicline-induced lowering of ICSS thresholds and the decrease in response latencies. 

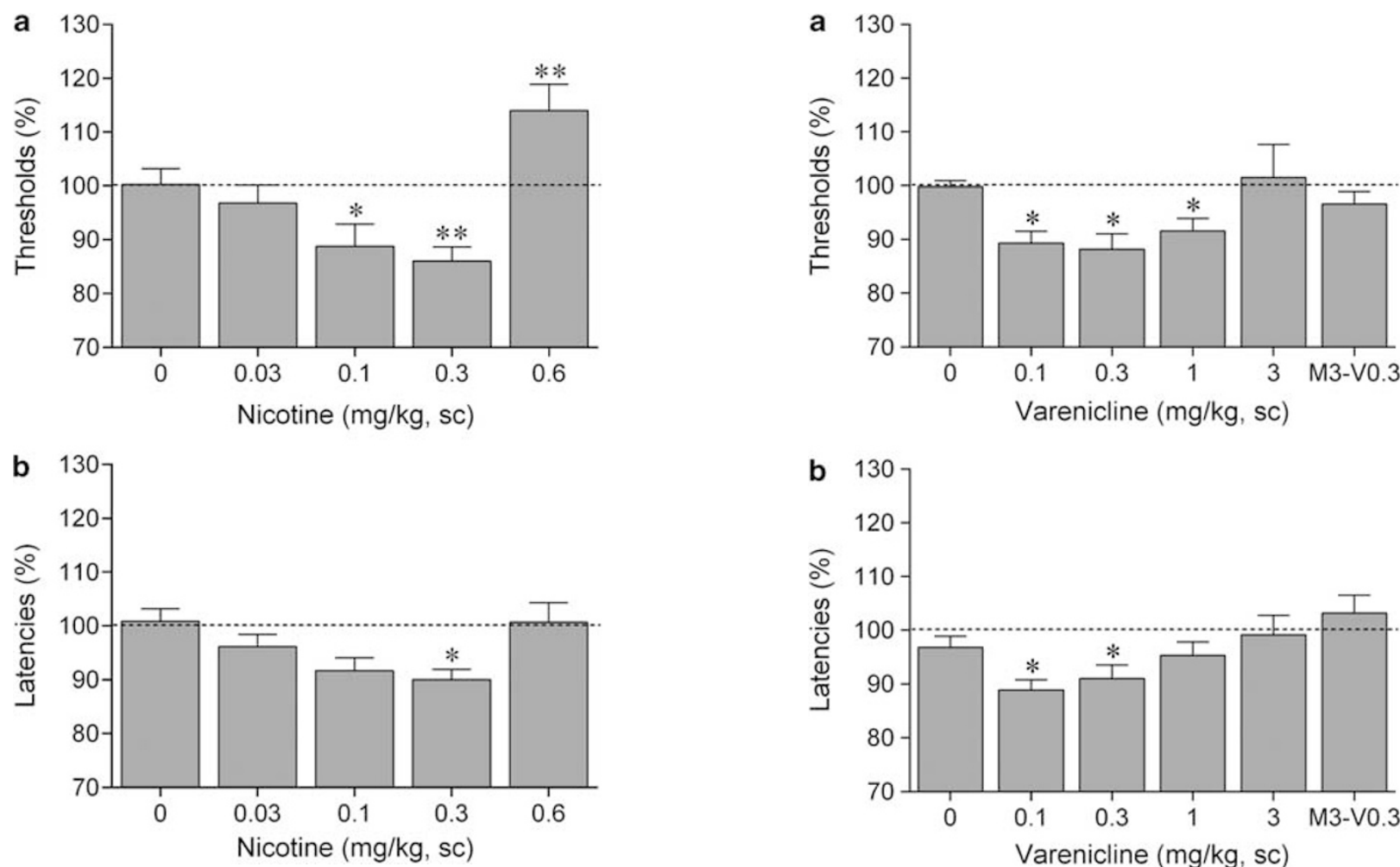

Figure I Nicotine potentiates brain reward function. (a) Acute nicotine lowers intracranial self-stimulation (ICSS) thresholds and (b) decreases response latencies. Asterisks $(* p<0.05$, $* * 0<0.0$ I) indicate lower ICSS thresholds or shorter response latencies compared with saline-treated rats. Data are expressed as means \pm SEM ( $n=12$ per group). Sc, subcutaneous.

Cytisine (Exp. 1.3). Cytisine did not affect ICSS thresholds $(\mathrm{F} 5,55=1.80, \mathrm{NS}$; Table 2$)$ or response latencies $(\mathrm{F} 5,55=0.91$, NS; Table 2).

3-Pyr-Cyt (Exp. 1.4). The cytisine derivative 3-pyr-Cyt did not affect ICSS thresholds (F3,36 = 1.69, NS; Table 2) or response latencies $(\mathrm{F} 3,36=1.44$, NS; Table 2$)$.

Experiments 2.1-2.3: Effect of Varenicline, Cytisine, and 3-Pyr-Cyt on Brain Reward Function in NicotineWithdrawing Rats

Mean ( \pm ) absolute ICSS thresholds and response latencies before minipump implantation and before minipump removal are shown in Table 3. Chronic administration of nicotine $(n=51)$ or saline $(n=37)$ did not affect ICSS thresholds. Chronic administration of nicotine $(n=51$, all groups combined) led to a small, but significant, decrease in the response latencies (prepump implantation $v s$ prepump removal; $t(50)=2.03, p<0.05$ ). There were no significant differences in ICSS thresholds or latencies between the various nicotine and saline groups before minipump removal (Table 3).

\section{Experiment 2.1: Effect of Varenicline on Brain Reward Function in Nicotine-Withdrawing Rats}

The removal of the nicotine pumps, but not saline pumps, led to elevations in ICSS thresholds (Pump: F1,41 $=41.62$,

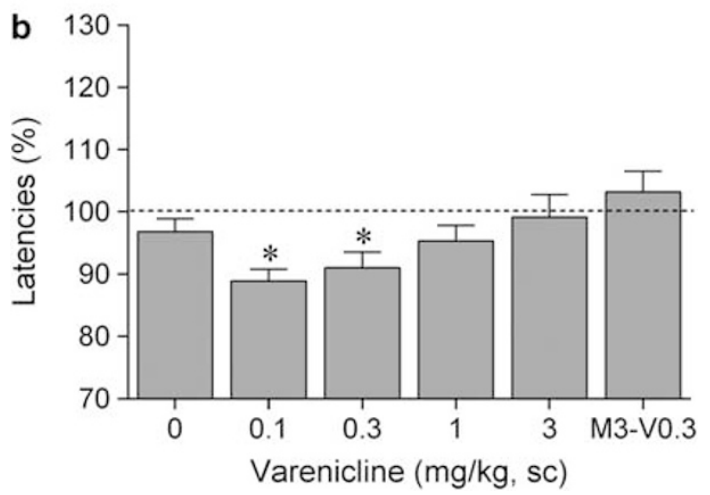

Figure 2 Varenicline potentiates brain reward function. (a) Acute varenicline lowers intracranial self-stimulation (ICSS) thresholds and (b) decreases response latencies. Asterisks $(* 0<0.05)$ indicate lower ICSS thresholds or shorter response latencies compared with saline. Data are expressed as means \pm SEM ( $n=9$ per group). M3, mecamylamine, $3 \mathrm{mg} / \mathrm{kg}$; sc, subcutaneous; $V 0.3$, varenicline $0.3 \mathrm{mg} / \mathrm{kg}$.

$p<0.001 ; \quad$ Pump $\times$ Time: $\quad \mathrm{F} 10,410=3.47, \quad p<0.001$; Figure 3a). Varenicline lowered ICSS thresholds and this effect was dependent on pump content (nicotine or saline) $($ Drug $\times$ Time: $\mathrm{F} 10,410=5.72, \quad p<0.001 ;$ Drug $\times$ Pump $\times$ Time: $\mathrm{F} 10,410=1.99, p<0.05)$. Additional two-way ANOVAs were conducted for the varenicline treatment period (12-72 h). These analyses showed that varenicline lowered the ICSS thresholds of the nicotine-withdrawing rats (Drug: $\mathrm{F} 1,25=14.97 ; p<0.001$ ). There was a trend toward a decrease in ICSS thresholds in the saline-control rats (after saline-pump removal) treated with varenicline, but this effect did not reach statistical significance (Drug: $\mathrm{F} 1,16=4.31, p=0.054)$.

Post hoc analyses indicated that in the nicotine-withdrawing rats treated with saline, the ICSS thresholds were elevated from 6 to $48 \mathrm{~h}$ after pump removal. In the nicotinewithdrawing rats treated with varenicline, the ICSS thresholds were only elevated at one time point $(36 \mathrm{~h})$. Varenicline diminished the elevations in ICSS thresholds associated with nicotine withdrawal. At the 12, 24, and $36 \mathrm{~h}$ time points, the ICSS thresholds were lower in the nicotinewithdrawing rats treated with varenicline than in the nicotine-withdrawing rats treated with saline. After the cessation of varenicline administration, there was an increase in the ICSS thresholds in the rats that had been exposed to the nicotine pumps $(96,120$, and $144 \mathrm{~h}$ time points). This suggests that cessation of varenicline administration leads to a dysphoric-like state in animals with a history of nicotine dependence. 
Table 2 Acute Effects of Cytisine and 3-pyr-Cyt on ICSS Thresholds and Response Latencies

\begin{tabular}{|c|c|c|c|c|c|c|}
\hline \multicolumn{7}{|c|}{ Cytisine (Exp. 1.3, $n=12$ ) } \\
\hline Dose $(\mathrm{mg} / \mathrm{kg})$ & 0 & 0.1 & 0.3 & 1 & 3 & 5 \\
\hline Thresh. $(\mu \mathrm{A})$ & $97.6 \pm 3.0$ & $101.6 \pm 2.5$ & $102.2 \pm 1.3$ & $98.8 \pm 1.6$ & $103.4 \pm 2.9$ & $105.9 \pm 4.3$ \\
\hline \multicolumn{7}{|c|}{ 3-pyr-Cyt (Exp. 1.4, $n=13$ ) } \\
\hline Dose (mg/kg) & 0 & 0.3 & 0.6 & 0.9 & & \\
\hline Thresh. $(\mu \mathrm{A})$ & $99.4 \pm 2.9$ & $100.0 \pm 2.6$ & $102.2 \pm 3.1$ & $106.5 \pm 4.2$ & & \\
\hline
\end{tabular}

Abbreviation: Thresh., ICSS thresholds.

Drugs were administered subcutaneously and data are expressed as a percentage of three-day baselines before the first drug injection.

Table 3 Absolute Baseline ICSS Thresholds and Response Latencies Before Minpump Implantation and Removal

\begin{tabular}{|c|c|c|c|c|c|c|}
\hline \multirow[t]{2}{*}{ Pump } & \multirow[t]{2}{*}{ Drug } & \multirow[t]{2}{*}{$N$} & \multicolumn{2}{|c|}{ Prepump implantation } & \multicolumn{2}{|c|}{ Prepump removal } \\
\hline & & & Threshold $(\mu \mathrm{A})$ & Latencies (s) & Threshold $(\mu \mathrm{A})$ & Latencies (s) \\
\hline Nicotine & & 51 & $101.6 \pm 3.5$ & $3.4 \pm 0.0$ & $102.6 \pm 3.5$ & $3.3 \pm 0.1 *$ \\
\hline Saline & Saline & 9 & $115.8 \pm 11.8$ & $3.4 \pm 0.1$ & $118.8 \pm 12.2$ & $3.3 \pm 0.1$ \\
\hline Saline & 3-pyr-Cyt & 9 & $94.3 \pm 4.0$ & $3.3 \pm 0.1$ & $95.6 \pm 3.6$ & $3.3 \pm 0.1$ \\
\hline Nicotine & Saline & 14 & $96.7 \pm 5.3$ & $3.2 \pm 0.1$ & $98.9 \pm 5.2$ & $3.2 \pm 0.1$ \\
\hline Nicotine & Varenicline & 13 & $106.9 \pm 8.5$ & $3.3 \pm 0.1$ & $107.4 \pm 8.6$ & $3.3 \pm 0.1$ \\
\hline Nicotine & Cytisine & 12 & $101.2 \pm 8.0$ & $3.4 \pm 0.1$ & $102.4 \pm 8.4$ & $3.2 \pm 0.1$ \\
\hline Nicotine & 3-pyr-Cyt & 12 & $102.1 \pm 6.1$ & $3.6 \pm 0.1^{++}$ & $105.0 \pm 5.5$ & $3.4 \pm 0.1^{*}$ \\
\hline
\end{tabular}

The ICSS thresholds and latencies are three-day baselines that were obtained on consecutive days before pump implantation or pump removal. Asterisks (* $p<0.05$ ) indicate difference between prepump-implantation and prepump-removal baselines within the same group. Plus signs $\left({ }^{+}+p<0.01\right)$ indicate significant difference compared with saline-pump/3-pyr-Cyt-inj group.

There were no main effects of Pump content or Drug treatment on the response latencies (Figure 3a). There was, however, a significant effect of Time (F10, $410=4.13$, $p<0.001), \quad$ Pump $\times$ Time interaction (F10, 410 $=3.49$, $p<0.001)$ and Drug $\times$ Time interaction $(\mathrm{F} 10,410=3.31$, $p<0.001)$. The post hoc comparisons revealed that varenicline decreased the response latencies in the saline-pump $(12 \mathrm{~h})$ and nicotine-pump rats $(72 \mathrm{~h})$. Furthermore, the latencies of the nicotine-withdrawing rats (nicotine-pump/ saline-inj) were slightly increased $(\sim 10 \%)$, but this did not reach statistical significance. Previous studies have also shown that cessation of nicotine administration leads to a small increase in response latencies (Bruijnzeel et al, 2007).

\section{Experiment 2.2: Effect of Cytisine on Brain Reward Function in Nicotine-Withdrawing Rats}

The removal of the nicotine pumps, but not saline pumps, led to elevations in the ICSS thresholds (Pump: $\mathrm{F} 1,41=13.75, \quad p<0.001$; Time: $\mathrm{F} 10,410=8.13, p<0.001$; Pump $\times$ Time: $\mathrm{F} 10,410=2.49, \quad p<0.01$; Figure $4 \mathrm{a}$ ). The administration of cytisine lowered ICSS thresholds and this effect was dependent on pump content (Pump $\times$ Drug $\times$ Time: $\mathrm{F} 10,410=4.95, p<0.001)$. The two-way ANOVA (12$72 \mathrm{~h}$ period) indicated that cytisine lowered the ICSS thresholds of the nicotine-withdrawing rats (Drug: F1,24 $=7.50, p<0.05$ ) but did not affect the ICSS thresholds of the saline-pump control rats (Drug: $F 1,17=3.62$, NS). The post hoc analyses indicated that at the $24 \mathrm{~h}$ time point, the ICSS thresholds of the nicotine-withdrawing animals treated with cytisine were lower than those of the nicotinewithdrawing rats treated with saline. Furthermore, cytisine reduced the duration of the elevations in ICSS thresholds in the nicotine-withdrawing rats ( $36 v s 48 \mathrm{~h}$ ). Nicotine withdrawal or pretreatment with cytisine did not affect the response latencies (Figure $4 \mathrm{~b}$ ). There was, however, a main effect of Time on response latencies (Time: F10,410 $=6.21$, $p<0.001$ ). This might have been caused by the removal of the minipumps (surgery effect). This led to a very small increase in response latencies and the latencies gradually returned to baseline levels. The post hoc analyses did not detect any differences in response latencies between the experimental groups.

\section{Experiment 2.3: Effect of 3-pyr-Cyt on Brain Reward Function in Nicotine-Withdrawing Rats}

Statistical analyses indicated that removal of the nicotine pumps led to an elevation in ICSS thresholds (Pump: $\mathrm{F} 1,40=49.00, p<0.001$; Time: $\mathrm{F} 10,400=5.17, \quad p<0.001$; 

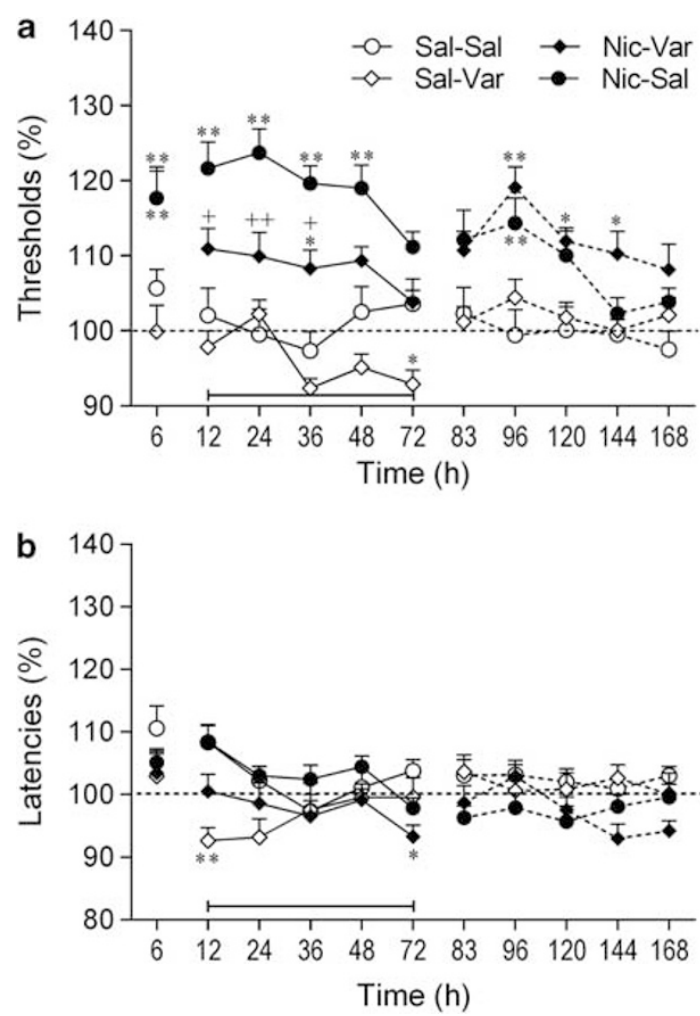

Figure 3 Varenicline diminishes the dysphoric-like state associated with nicotine withdrawal. (a) Effect of varenicline on the elevations in intracranial self-stimulation (ICSS) threshold associated with spontaneous nicotine withdrawal. (b) Effect of varenicline on response latencies. The number of animals per group was: saline-saline, $n=9$; saline-varenicline, $n=9$; nicotine-saline, $n=14$; and nicotine-varenicline, $n=13$. (a) At the $6 \mathrm{~h}$ time point, the ICSS thresholds of the nicotine-saline rats and the nicotinevarenicline rats were similar (117\% of baseline). Therefore, only one data point is visible for these two groups. Asterisks $(* p<0.05$, $* * 0<0.0 \mathrm{I})$ indicate elevated ICSS thresholds compared with the saline-saline group. Plus signs $\left({ }^{+} p<0.05,{ }^{+}+p<0.0 \mathrm{I}\right)$ indicate lower ICSS thresholds compared with nicotine-saline group. (b) Asterisks (*p $<0.05$, $* * p<0.0$ I) indicate shorter latencies compared with saline-saline group. Three specific periods are depicted in the figures (before, during, and after varenicline treatment) and these periods are separated by line breaks. The bar at the bottom of each figure indicates the varenicline treatment period. The rats received varenicline or saline before each time point (12-72 h). Data are expressed as means \pm SEM. Nic, nicotine; Sal, saline; Var, varenicline.

Pump $\times$ Time: $\mathrm{F} 10,400=8.61, p<0.001$; Figure 5a). The overall three-way ANOVA indicated that 3-pyr-Cyt did not affect the ICSS thresholds. The three-way ANOVA analyses indicated that the latencies of the nicotinewithdrawing rats were longer than the latencies of the saline control rats (Time: F10,400 $=7.77, p<0.001$; Pump $\times$ Time: $\mathrm{F} 10,400=3.58, p<0.001$; Figure $5 \mathrm{~b}$ ). The statistical analyses also revealed a trend towards a Pump $\times$ Drug interaction $(\mathrm{F} 1,40=3.48, p=0.07)$, which suggests that the effects of 3-pyr-Cyt on the latencies depend on the treatment history (chronic nicotine or saline). The post hoc test indicated that 3-pyr-Cyt increased the latencies in the nicotine-withdrawing rats ( $36 \mathrm{~h}$ time point) but not in the control rats.

An additional statistical analysis was conducted to compare the effects of all three drugs (varenicline, cytisine, and 3-pyr-Cyt) on nicotine withdrawal (12-72 h). This study
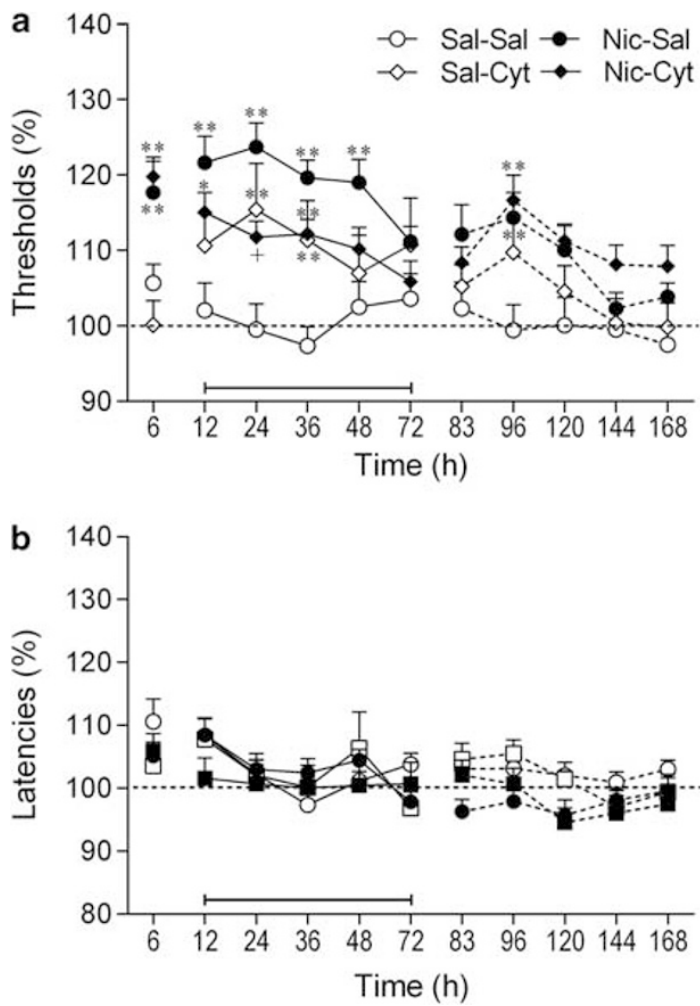

Figure 4 Cytisine diminishes the dysphoric-like state associated with nicotine withdrawal. (a) Effect of cytisine on the elevation in intracranial selfstimulation (ICSS) thresholds associated with spontaneous nicotine withdrawal. (b) Effect of cytisine on response latencies. The number of animals per group was: saline-saline, $n=9$; saline-cytisine, $n=10$; nicotine-saline, $n=14$; and nicotine-cytisine, $n=12$. Asterisks (*p $<0.05$, $* * p<0.01$ ) indicate elevated ICSS thresholds compared with the saline-saline group. Plus sign $\left({ }^{+} p<0.05\right)$ indicates lower ICSS thresholds compared with nicotine-saline group. Three specific periods are depicted in the figures (before, during, and after cytisine treatment) and these periods are separated by line breaks. The bar at the bottom of each figure indicates the cytisine treatment period. The rats received cytisine or saline before each time point ( $12-72 \mathrm{~h})$. Data are expressed as means \pm SEM. Cyt, cytosine; Nic, nicotine; Sal, saline.

showed that the drug treatments affected the ICSS thresholds of the nicotine-withdrawing rats and that the thresholds of these rats returned to baseline levels over time (Drug: $\mathrm{F} 3,47=14.04, \quad p<0.001 ; \quad$ Time: $\mathrm{F} 4,188=10.05$, $p<0.001)$. The post hoc comparisons indicated that there was no difference in ICSS thresholds between the nicotinewithdrawing rats treated with varenicline or cytisine (12$72 \mathrm{~h}$ ). Furthermore, the ICSS thresholds of the nicotinewithdrawing rats treated with varenicline $(p<0.01)$ or cytisine $(p<0.05)$ were lower than those of the nicotinewithdrawing rats treated with saline. The ICSS thresholds of the nicotine-withdrawing rats treated with varenicline $(p<0.001)$ or cytisine $(p<0.001)$ were also lower than those of the nicotine-withdrawing rats treated with 3-pyr-Cyt.

An AUC analysis was conducted to compare the cumulative effects of the various treatments on ICSS thresholds during the treatment period $(12-72 \mathrm{~h})$. The AUC was calculated using the following formula: $A U C=\left(\sum_{i=1}^{n-1} \frac{\left(m(i+1)+m_{i}\right) \times t_{i}}{2}\right)-($ baseline $\times$ time $)$ (Pruessner et al, 2003). In this formula, $t_{i}$ indicates the 

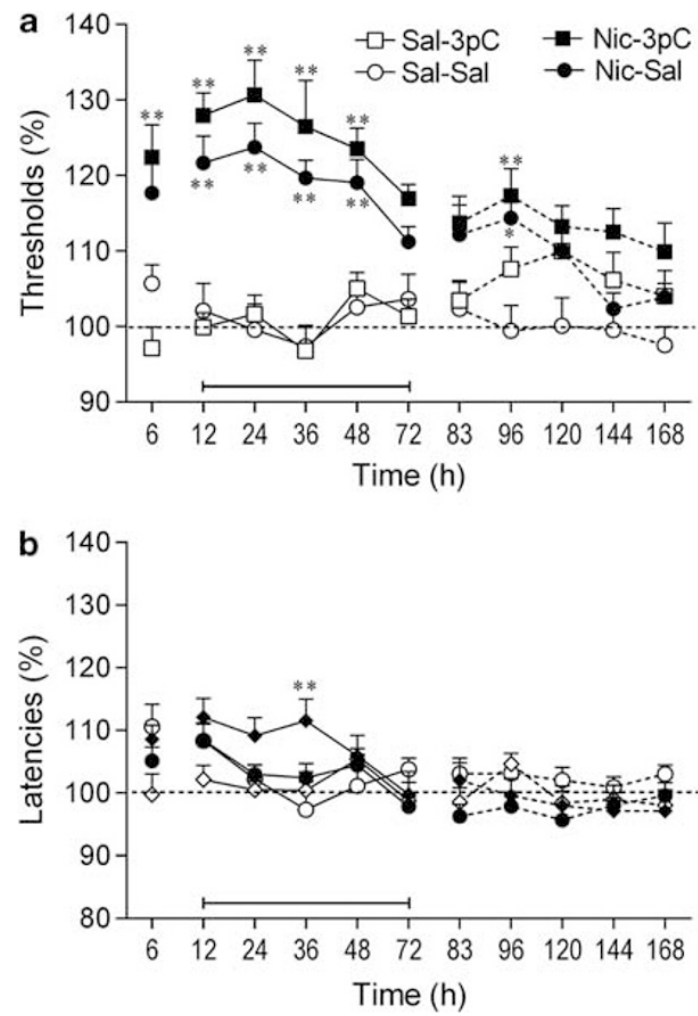

Figure 5 The cytisine derivative 3-pyr-Cyt does not affect the dysphoriclike state associated with nicotine withdrawal. (a) Effect of 3-pyr-Cyt on the elevation in intracranial self-stimulation (ICSS) thresholds associated with spontaneous nicotine withdrawal. (b) Effect of 3-pyr-Cyt on response latencies. The number of animals per group was: saline-saline, $n=9$; saline3-pyr-Cyt, $n=9$; nicotine-saline, $n=14$; and nicotine-3-pyr-Cyt, $n=12$. Asterisks $(* p<0.05, * * 0<0.01)$ indicate elevated ICSS thresholds or increased response latencies compared with the saline-saline group. Three specific periods are depicted in the figures (before, during, and after 3-pyrCyt-treatment) and these periods are separated by line breaks. The bar at the bottom of each figure indicates the 3-pyr-Cyt treatment period. The rats received 3-pyr-Cyt or saline before each time point ( $12-72 \mathrm{~h}$ ). Data are expressed as means \pm SEM. Nic, nicotine; Sal, saline.

time distance between the points at which ICSS thresholds were assessed, $m_{i}$ indicates the ICSS thresholds at a specific time point, $n$ the number of time points, the baseline is 100 (see Figures 3-5), and time is the treatment period $(60 \mathrm{~h}$ ). The ANOVA analysis indicated that ICSS thresholds were elevated in the nicotine-withdrawing rats and that the drug treatments (varenicline, cytisine, and 3-pyr-Cyt) differentially affected the nicotine-withdrawing and the control rats (Pump: F1, $80=59.50, p<0.001$; Drug: F3, $80=$ 7.50, $p<0.001$; Pump $\times$ Drug interaction: F3, $80=8.38$, $p<0.001$; Figure 6). Dunnett $t$-tests comparisons indicated that varenicline and cytisine lowered the ICSS thresholds of the nicotine-withdrawing rats. Furthermore, cytisine elevated the ICSS thresholds of the saline-treated control rats and 3-pyr-Cyt did not affect the ICSS thresholds of the nicotine-withdrawing rats or the saline-pump control rats.

\section{DISCUSSION}

The present studies investigated the effects of varenicline, cytisine, and 3-pyr-Cyt on ICSS thresholds in nicotine-naive

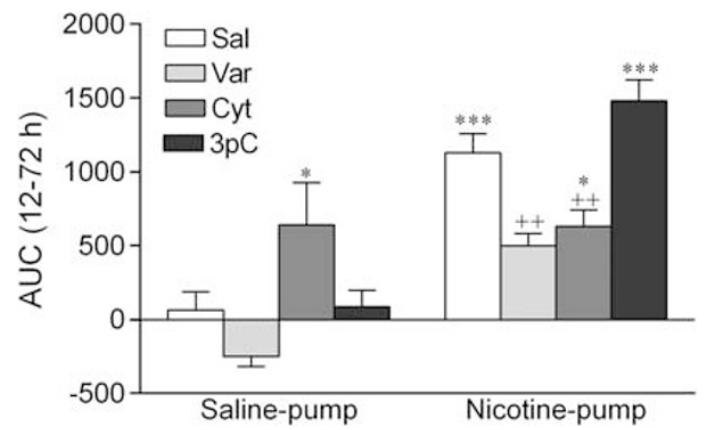

Figure 6 Area under the curve (AUC) analyses for the effects of varenicline, cytisine, and 3-pyr-Cyt on nicotine withdrawal-induced elevations in intracranial self-stimulation (ICSS) thresholds. The treatment period was from $12-72 \mathrm{~h}$ after removal of the minipumps. The number of animals per group was: saline-saline, $n=9$; saline-varenicline, $n=9$; salinecytisine, $n=10$; saline-3-pyr-Cyt, $n=9$; nicotine-saline, $n=14$; nicotinevarenicline, $n=13$; nicotine-cytisine, $n=12$; and nicotine-3-pyr-Cyt, $n=12$. Asterisks $(* p<0.05$, $* * * x<0.00 I)$ indicate higher ICSS thresholds compared with saline-saline group. Plus signs $\left({ }^{+}{ }^{+} p<0.0\right.$ I) indicate lower ICSS thresholds compared with nicotine-saline group. Data are expressed as means \pm SEM. Cyt, cytisine; 3pC, 3-pyr-Cyt; Nic, nicotine; Sal, saline; Var, varenicline.

and nicotine-withdrawing rats. The first series of experiments showed that nicotine and varenicline, but not cytisine or 3-pyr-Cyt, lowered ICSS thresholds in nicotine-naive rats. The second series of experiments showed that varenicline and cytisine, but not 3-pyr-Cyt, diminishes the elevations in ICSS thresholds associated with nicotine withdrawal. These findings indicate that varenicline potentiates brain reward function and diminishes the dysphoric-like state associated with nicotine withdrawal. Cytisine does not potentiate brain reward function but, like varenicline, also diminishes the dysphoric-like state associated with nicotine withdrawal.

The first set of experiments showed that the effects of nicotine and varenicline on ICSS thresholds in nicotinenaive rats are somewhat similar. Both nicotine and varenicline produced an inverted U-shaped dose-effect curve. Low doses of nicotine and varenicline did not affect ICSS thresholds and medium doses lowered ICSS thresholds. A high dose of nicotine $(0.6 \mathrm{mg} / \mathrm{kg}$ nicotine base $)$ elevated the thresholds above baseline levels, whereas a high dose of varenicline $(1.8 \mathrm{mg} / \mathrm{kg}$ base or $3 \mathrm{mg} / \mathrm{kg}$ salt; MW varenicline salt: $361.35 \mathrm{Da}$, MW varenicline base: $211.27 \mathrm{Da}$ ) did not affect ICSS thresholds. The effects of nicotine on ICSS thresholds are in line with a previous study that showed that low, but not high, doses of nicotine lower ICSS thresholds (Kenny et al, 2009). In this study by Kenny et al (2009), the highest dose of nicotine $(0.5 \mathrm{mg} / \mathrm{kg}$ base $)$ did not elevate ICSS thresholds above baseline levels. This nicotine dose was slightly lower than the highest nicotine dose in the present study $(0.6 \mathrm{mg} / \mathrm{kg}$ base $)$ and therefore it is likely that a slightly higher dose would have elevated the ICSS thresholds above baseline levels. Place conditioning studies have also shown that low doses of nicotine are rewarding (ie, place preference) and that high doses of nicotine are aversive (ie, place aversion)(Le Foll and Goldberg 2005; Fudala et al, 1985). It should be noted that one study has reported that a high dose of nicotine $(0.5 \mathrm{mg} / \mathrm{kg}$ base $)$ can lower ICSS thresholds (Harrison et al, 2002). This study is 
not in line with the present ICSS study (Figure 1a) or another ICSS study by the same research group (Kenny et al, 2009). At this point, it is not clear what caused this discrepancy between these studies, but it should be noted that Harrison et al (2002) also reported a much greater nicotine-induced decrease in ICSS thresholds. The present study and Kenny et al (2009) showed that nicotine lowers the ICSS thresholds by $10-15 \%$, whereas Harrison et al (2002) reported a $25-30 \%$ decrease in ICSS thresholds. It is unlikely that these differences were due to differences in rat strains or test procedures because male wistar rats were used for all these studies and the same test procedure was used to assess ICSS thresholds.

In the present study, one noteworthy difference between the nicotine and the varenicline dose-effect curves was the dose range that lowered ICSS thresholds. In the nicotine study, low doses of nicotine lowered ICSS thresholds, but the highest dose $(0.6 \mathrm{mg} / \mathrm{kg}$ of nicotine base) elevated ICSS thresholds. In contrast, low doses of varenicline and a relatively high dose $(0.6 \mathrm{mg} / \mathrm{kg}$ of varenicline base, equivalent to $1 \mathrm{mg} / \mathrm{kg}$ varenicline salt) lowered ICSS thresholds. Thus, $0.6 \mathrm{mg} / \mathrm{kg}$ of nicotine base has aversive effects and the same dose of varenicline has rewarding effects. This difference between nicotine and varenicline might be due to the fact that varenicline has a lower efficacy for a variety of nAChRs (Papke et al, 2011). The maximal efficacy of varenicline for the $\alpha 4 \beta 2 \mathrm{nAChR}$ receptor is only $24 \%$ of that of nicotine (Coe et al, 2005). More importantly, a recent study showed that the efficacy of nicotine for the $\alpha 4 \beta 2 \alpha 5$ nAChR was $35 \%$ that of acetylcholine, whereas the efficacy of varenicline was only $9 \%$ of that of acetylcholine (Papke et al, 2011). The activation of $\alpha 5^{\star} \mathrm{nAChRs}$ in the medial habenula has an important role in the aversive effects of nicotine (Fowler et al, 2011). Therefore, it could be speculated that the low efficacy of varenicline for the $\alpha 5^{*}$ nAChR explains the fact that a relatively high dose of varenicline $(0.6 \mathrm{mg} / \mathrm{kg}$ base $)$ has rewarding effects, whereas a similar dose of nicotine $(0.6 \mathrm{mg} / \mathrm{kg}$ base $)$ has aversive effects.

In the present study, cytisine did not affect the ICSS thresholds of nicotine-naive rats. This would suggest that cytisine does not potentiate brain reward function. Very few studies have compared the effects of nicotine, cytisine, and varenicline on the brain reward system. Cytisine and varenicline have a similar affinity and efficacy for the nAChRs $\left(\alpha 4 \beta 2^{*}, \alpha 6 \beta 2^{*}\right)$ that mediate the rewarding effects of nicotine (Papke et al, 2010; Grady et al, 2010; Picciotto and Kenny, 2013). Therefore, it is unlikely that the differences between varenicline and cytisine on ICSS thresholds are due to differences in nAChR binding and efficacy. One study compared the maximum nicotine, cytisine, and varenicline-induced increase in dopamine turnover in the nucleus accumbens (Coe et al, 2005). Nicotine (subcutaneously) induced a $177 \%$ increase in dopamine turnover in the nucleus accumbens and the effect of cytisine (subcutaneously) and varenicline (subcutaneously) were 40 and $32 \%$ of those of nicotine. In a similar study, nicotine (subcutaneously) induced a $180 \%$ increase in dopamine turnover in the nucleus accumbens and orally administered varenicline and cytisine induced a 130-140\% increase in dopamine turnover (Rollema et al, 2010). Importantly, the same study showed that orally administered varenicline and cytisine are rapidly and completely absorbed into the circulation (Rollema et al, 2010). Taken together, these studies suggest that cytisine and varenicline induce a similar increase in dopamine levels, but both these drugs are less efficacious than nicotine. In the same study, it was shown that varenicline was 20 times more potent in increasing dopamine turn over than cytisine. This is most likely because systemic administration of cytisine leads to relatively low levels of this drug in the brain (Rollema et al, 2010). Oral administration of cytisine and varenicline leads to similar plasma levels, but the plasma / brain ratio is 3.9 for varenicline and 0.11 for cytisine (Rollema et al, 2010). It has been suggested that varenicline and cytisine readily enter the brain, but that cytisine is removed via an active efflux mechanism (Rollema et al, 2010). Therefore, it might be possible that acute cytisine does not lower ICSS thresholds in nicotine-naive rats because it is rapidly removed from the brain. In the present study, the cytisine derivative 3-pyr-Cyt did affect ICSS thresholds. Low doses did not affect ICSS thresholds and higher doses tended to elevate the ICSS thresholds. This is mostly likely due to the fact that this compound is a very weak partial agonist at $\alpha 4 \beta 2^{*}$ nAChRs and at high doses diminishes acetylcholine transmission (Mineur et al, 2009; Papke et al, 2010).

The second set of experiments showed that varenicline and cytisine, but not 3-pyr-Cyt, diminishes the elevations in ICSS thresholds associated with nicotine withdrawal. A close look at the data indicates that the ICSS thresholds in the nicotine-withdrawing rats treated with saline were elevated for 2 days (6-72 h). In the nicotine-withdrawing rats treated with varenicline, the ICSS thresholds were only elevated at one time point $(36 \mathrm{~h})$, and in the nicotinewithdrawing rats treated with cytosine, the ICSS thresholds were elevated at two time points (12 and $36 \mathrm{~h})$. This pattern of results would suggest that varenicline is slightly more effective than cytisine in diminishing the dysphoric-like state associated with nicotine withdrawal. However, an additional ANOVA analysis indicated that there was no significant difference in ICSS thresholds between the nicotine-withdrawing rats treated with varenicline or cytisine. These findings suggest that both varenicline and cytisine diminish the dysphoric-like state associated with nicotine withdrawal. The administration of 3-pyr-Cyt did not diminish the elevations in ICSS thresholds associated with nicotine withdrawal. At all time points, the ICSS thresholds of the nicotine-withdrawing rats treated with 3-pyr-Cyt were higher than those of nicotine-withdrawing rats treated with saline. There were, however, no significant differences between the nicotine-withdrawing rats treated with saline or 3-pyr-Cyt. It has been reported that 3-pyr-Cyt is a very weak partial agonist at $\alpha 4 \beta 2^{*} \mathrm{nAChRs}$ (Mineur et al, 2009; Papke et al, 2011). The present data suggest that a very weak partial agonist at $\alpha 4 \beta 2^{*}$ nAChRs does not attenuate the elevations in ICSS thresholds associated with nicotine withdrawal and might therefore not diminish the negative mood state associated with smoking cessation.

After the cessation of varenicline, cytisine, and 3-pyr-Cyt administration, the ICSS thresholds were assessed for an additional 4 days. The ICSS thresholds of the nicotinewithdrawing rats treated with saline, cytisine, or 3-pyr-Cyt were elevated at one time point $(96 \mathrm{~h})$. However, the ICSS thresholds of the nicotine-withdrawing rats treated with varenicline were elevated for an additional 2 days 
(96-114h). Cessation of varenicline administration did not lead to elevations in ICSS thresholds in the rats that were chronically treated with saline (saline-pump group). One possible explanation for the elevations in ICSS thresholds after the cessation of varenicline administration is that nicotine addiction is at least partly mediated by a nicotineinduced upregulation and desensitization of nAChRs (Dani and Balfour, 2011). Varenicline might maintain this state and therefore cessation of varenicline administration might lead to delayed nicotine withdrawal signs (Hussmann et al, 2012). The present finding would suggest that cessation of varenicline use in former smokers could lead to a dysphoric state. To our knowledge, the effect of varenicline withdrawal on mood states has not been thoroughly investigated in large clinical trials. There are, however, some case reports that indicate that cessation of varenicline intake in former smokers can lead to agitation, anxiety, and hallucinations and these symptoms gradually resolve over time (May and Rose, 2010; Laine et al, 2009).

The present study showed that cytisine is as effective as varenicline in diminishing nicotine withdrawal and there are no delayed withdrawal signs. Cytisine might also be given additional consideration as smoking cessation aid because cytisine has a lower sensitivity than varenicline for human $\alpha 3 \beta 4^{*} \mathrm{nAChRs}$ (ganglionic receptor) (Stokes and Papke, 2012). The $\alpha 3 \beta 4^{*}$ nAChR is highly expressed in brain stem areas involved in cardiovascular control and stimulation of these receptors may increase the risk for cardiovascular disorders (Sobieraj et al, 2013; Perry et al, 2002).

At the end of the studies, the AUC was calculated for the various nicotine and saline groups. This was carried out to investigate the cumulative effects of the various treatments on ICSS thresholds during the drug treatment period (12$72 \mathrm{~h}$ ). These data confirm that varenicline and cytisine diminish the elevations in ICSS thresholds associated with nicotine withdrawal to a similar degree. It was interesting to note that the ICSS thresholds in the saline-pump/cytisineinj group were elevated. This indicates that repeated administration of a high dose of cytisine lowers ICSS thresholds in the nicotine-withdrawing rats, but elevates ICSS thresholds in the drug-naive control rats. This is in line with the observation that high doses of nicotinic receptor agonists have aversive effects (Spiller et al, 2009; Le Foll and Goldberg, 2005; Fudala et al, 1985). However, as can be seen in Figure 4a, the rats rapidly develop tolerance to the aversive effects of cytisine, whereas cytisine continues to prevent the elevations in ICSS thresholds associated with nicotine withdrawal.

It has been suggested that drugs that lower ICSS thresholds are more likely to be abused than drugs that do not affect ICSS thresholds or elevate ICSS thresholds (Kornetsky et al, 1979). Indeed, widely abused drugs such as cocaine and amphetamine lower ICSS thresholds (Kornetsky and Esposito, 1979; Cryan et al, 2003). However, despite the fact that varenicline lowers ICSS thresholds, it has been suggested that its abuse liability is extremely low (McColl et al, 2008). This might be because the doseresponse window for nicotinic receptor agonists to potentiate brain reward function in humans is very narrow and higher doses induce negative side effects such as nausea (McColl et al, 2008). Although the abuse liability of varenicline is low, there is evidence that varenicline can have unintended side effects in certain psychiatric patients. For example, clinical evidence indicates that varenicline can precipitate manic episodes in people with bipolar disorder (Hussain et al, 2011; Alhatem and Black, 2009; Francois et al, 2011; Knibbs and Tsoi, 2011). Therefore, some caution with the use of varenicline in psychiatric patients is warranted.

In conclusion, the present studies indicate that varenicline and cytisine diminish the dysphoric-like state associated with spontaneous nicotine withdrawal in rats. It is suggested that these smoking cessation aids may prevent relapse to smoking in humans by diminishing the negative mood state associated with smoking cessation.

\section{FUNDING AND DISCLOSURE}

The authors declare no conflict of interest.

\section{ACKNOWLEDGEMENTS}

This work was funded by a James and Esther King Biomedical Research Program Grant (1KG12) to RP and $A B$, and a National Institute on Drug Abuse (DA023575) and Flight Attendant Medical Research Institute (Grant 52312) to $\mathrm{AB}$.

\section{REFERENCES}

Alhatem F, Black JE (2009). Varenicline-induced mania in a bipolar patient. Clin Neuropharmacol 32: 117-118.

American Psychiatric Association (2000). Diagnostic and Statistical Manual of Mental Disorders. American Psychiatric Press: Washington, DC, USA.

Barr AM, Markou A, Phillips AG (2002). A 'crash' course on psychostimulant withdrawal as a model of depression. Trends Pharmacol Sci 23: 475-482.

Biala G, Staniak N, Budzynska B (2010). Effects of varenicline and mecamylamine on the acquisition, expression, and reinstatement of nicotine-conditioned place preference by drug priming in rats. Naunyn Schmiedebergs Arch Pharmacol 381: 361-370.

Bruijnzeel AW (2012). Tobacco addiction and the dysregulation of brain stress systems. Neurosci Biobehav Rev 36: 1418-1441.

Bruijnzeel AW, Ford J, Rogers JA, Scheick S, Ji Y, Bishnoi M et al (2012). Blockade of CRF1 receptors in the central nucleus of the amygdala attenuates the dysphoria associated with nicotine withdrawal in rats. Pharmacol Biochem Behav 101: 62-68.

Bruijnzeel AW, Prado M, Isaac S (2009). Corticotropin-releasing factor-1 receptor activation mediates nicotine withdrawalinduced deficit in brain reward function and stress-induced relapse. Biol Psychiatry 66: 110-117.

Bruijnzeel AW, Zislis G, Wilson C, Gold MS (2007). Antagonism of $\mathrm{CRF}$ receptors prevents the deficit in brain reward function associated with precipitated nicotine withdrawal in rats. Neuropsychopharmacology 32: 955-963.

Changeux JP (2010). Nicotine addiction and nicotinic receptors: lessons from genetically modified mice. Nat Rev Neurosci 11: 389-401.

Coe JW, Brooks PR, Vetelino MG, Wirtz MC, Arnold EP, Huang J et al (2005). Varenicline: an alpha4beta2 nicotinic receptor partial agonist for smoking cessation. J Med Chem 48: 3474-3477.

Cryan JF, Hoyer D, Markou A (2003). Withdrawal from chronic amphetamine induces depressive-like behavioral effects in rodents. Biol Psychiatry 54: 49-58. 
Dani JA, Balfour DJ (2011). Historical and current perspective on tobacco use and nicotine addiction. Trends Neurosci 34: 383-392.

Dani JA, Bertrand D (2007). Nicotinic acetylcholine receptors and nicotinic cholinergic mechanisms of the central nervous system. Annu Rev Pharmacol Toxicol 47: 699-729.

Debruyne D, Sobrio F, Hinschberger A, Camsonne R, Coquerel A, Barre L (2003). Short-term pharmacokinetics and brain distribution of mecamylamine as a preliminary to carbon-11 labeling for nicotinic receptor investigation. J Pharm Sci 92: 1051-1057.

Dunnett CW (1955). A multiple comparison procedure for comparing several treatments with a control. J. Am. Stat. Assoc. 50: $1096-1121$.

Epping-Jordan MP, Watkins SS, Koob GF, Markou A (1998). Dramatic decreases in brain reward function during nicotine withdrawal. Nature 393: 76-79.

Etter JF (2006). Cytisine for smoking cessation: a literature review and a meta-analysis. Arch Intern Med 166: 1553-1559.

Fowler CD, Lu Q, Johnson PM, Marks MJ, Kenny PJ (2011). Habenular alpha5 nicotinic receptor subunit signalling controls nicotine intake. Nature 471: 597-601.

Francois D, Odom A, Kotbi N (2011). A case of late-life onset mania during varenicline assisted smoking cessation. Int $J$ Geriatr Psychiatry 26: 658-659.

Fudala PJ, Teoh KW, Iwamoto ET (1985). Pharmacologic characterization of nicotine-induced conditioned place preference. Pharmacol Biochem Behav 22: 237-241.

Gourlay SG, Stead LF, Benowitz N (2004). Clonidine for smoking cessation. Cochrane Database Syst Rev 3: Art. No.: CD000058. pub2.

Grady SR, Drenan RM, Breining SR, Yohannes D, Wageman CR, Fedorov NB et al (2010). Structural differences determine the relative selectivity of nicotinic compounds for native alpha 4 beta $2^{*}$, alpha 6 beta $2^{*}$-, alpha 3 beta $4^{*}$ - and alpha 7 -nicotine acetylcholine receptors. Neuropharmacology 58: 1054-1066.

Harrison AA, Gasparini F, Markou A (2002). Nicotine potentiation of brain stimulation reward reversed by $\mathrm{DH} \beta \mathrm{E}$ and $\mathrm{SCH} 23390$, but not by eticlopride, LY 314582 or MPEP in rats. Psychopharmacology (Berl) 160: 56-66.

Hussain S, Kayne E, Guwanardane N, Petrides G (2011). Varenicline induced mania in a 51 year old patient without history of bipolar illness. Prog Neuropsychopharmacol Biol Psychiatry 35: 1162-1163.

Hussmann GP, Turner JR, Lomazzo E, Venkatesh R, Cousins V, Xiao $Y$ et al (2012). Chronic sazetidine-A at behaviorally active doses does not increase nicotinic cholinergic receptors in rodent brain. J Pharmacol Exp Ther 343: 441-450.

Jackson KJ, Sanjakdar SS, Muldoon PP, McIntosh JM, Damaj MI (2013). The alpha3beta4* nicotinic acetylcholine receptor subtype mediates nicotine reward and physical nicotine withdrawal signs independently of the alpha5 subunit in the mouse. Neuropharmacology 70: 228-235.

Jorenby DE, Hays JT, Rigotti NA, Azoulay S, Watsky EJ, Williams KE et al (2006). Efficacy of varenicline, an alpha4beta2 nicotinic acetylcholine receptor partial agonist, $v s$ placebo or sustainedrelease bupropion for smoking cessation: a randomized controlled trial. JAMA 296: 56-63.

Kenny PJ, Chartoff E, Roberto M, Carlezon WA Jr., Markou A (2009). NMDA receptors regulate nicotine-enhanced brain reward function and intravenous nicotine self-administration: role of the ventral tegmental area and central nucleus of the amygdala. Neuropsychopharmacology 34: 266-281.

Knibbs N, Tsoi DT (2011). Varenicline induces manic relapse in bipolar disorder. Gen Hosp Psychiatry 33: 641-642.

Koob GF, Volkow ND (2010). Neurocircuitry of addiction. Neuropsychopharmacology 35: 217-238.

Kornetsky C, Esposito RU (1979). Euphorigenic drugs: effects on the reward pathways of the brain. Fed Proc 38: 2473-2476.
Kornetsky C, Esposito RU, McLean S, Jacobson JO (1979). Intracranial self-stimulation thresholds: a model for the hedonic effects of drugs of abuse. Arch Gen Psychiatry 36: 289-292.

Kyerematen GA, Owens GF, Chattopadhyay B, deBethizy JD, Vesell ES (1988). Sexual dimorphism of nicotine metabolism and distribution in the rat. Studies in vivo and in vitro. Drug Metab Dispos 16: 823-828.

Laine P, Marttila J, Lindeman S (2009). Hallucinations in the context of varenicline withdrawal. Am J Psychiatry 166: 619-620.

Le Foll B, Goldberg SR (2005). Nicotine induces conditioned place preferences over a large range of doses in rats. Psychopharmacology (Berl) 178: 481-492.

LeSage MG, Shelley D, Ross JT, Carroll FI, Corrigall WA (2009). Effects of the nicotinic receptor partial agonists varenicline and cytisine on the discriminative stimulus effects of nicotine in rats. Pharmacol Biochem Behav 91: 461-467.

Leslie FM, Mojica CY, Reynaga DD (2013). Nicotinic receptors in addiction pathways. Mol Pharmacol 83: 753-758.

Liu L, Zhao-Shea R, McIntosh JM, Gardner PD, Tapper AR (2012). Nicotine persistently activates ventral tegmental area dopaminergic neurons via nicotinic acetylcholine receptors containing alpha4 and alpha6 subunits. Mol Pharmacol 81: 541-548.

Marcinkiewcz CA, Prado MM, Isaac SK, Marshall A, Rylkova D, Bruijnzeel AW (2009). Corticotropin-releasing factor within the central nucleus of the amygdala and the nucleus accumbens shell mediates the negative affective state of nicotine withdrawal in rats. Neuropsychopharmacology 34: 1743-1752.

Markou A, Koob GF (1992). Construct validity of a self-stimulation threshold paradigm: effects of reward and performance manipulations. Physiol Behav 51: 111-119.

Markou A, Paterson NE (2001). The nicotinic antagonist methyllycaconitine has differential effects on nicotine self-administration and nicotine withdrawal in the rat. Nicotine Tob Res 3: 361-373.

May AC, Rose D (2010). Varenicline withdrawal-induced delirium with psychosis. Am J Psychiatry 167: 720-721.

McColl SL, Burstein AH, Reeves KR, Billing CB Jr, Stolar M, Sellers EM (2008). Human abuse liability of the smoking cessation drug varenicline in smokers and nonsmokers. Clin Pharmacol Ther 83: 607-614.

Mihalak KB, Carroll FI, Luetje CW (2006). Varenicline is a partial agonist at alpha4beta2 and a full agonist at alpha7 neuronal nicotinic receptors. Mol Pharmacol 70: 801-805.

Mineur YS, Eibl C, Young G, Kochevar C, Papke RL, Gundisch D et al (2009). Cytisine-based nicotinic partial agonists as novel antidepressant compounds. J Pharmacol Exp Ther 329: 377-386.

Museo E, Wise RA (1994a). Place preference conditioning with ventral tegmental injections of cytisine. Life Sci 55: 1179-1186.

Museo E, Wise RA (1994b). Sensitization of locomotion following repeated ventral tegmental injections of cytisine. Pharmacol Biochem Behav 48: 521-524.

Obach RS, Reed-Hagen AE, Krueger SS, Obach BJ, O'Connell TN, Zandi KS et al (2006). Metabolism and disposition of varenicline, a selective alpha4beta2 acetylcholine receptor partial agonist, in vivo and in vitro. Drug Metab Dispos 34: 121-130.

Papke RL, Trocme-Thibierge C, Guendisch D, Al Rubaiy SA, Bloom SA (2011). Electrophysiological perspectives on the therapeutic use of nicotinic acetylcholine receptor partial agonists. J Pharmacol Exp Ther 337: 367-379.

Papke RL, Wecker L, Stitzel JA (2010). Activation and inhibition of mouse muscle and neuronal nicotinic acetylcholine receptors expressed in Xenopus oocytes. J Pharmacol Exp Ther 333: 501-518.

Perry DC, Xiao Y, Nguyen HN, Musachio JL, Davila-Garcia MI, Kellar KJ (2002). Measuring nicotinic receptors with characteristics of alpha4beta2, alpha3beta2 and alpha3beta4 subtypes in rat tissues by autoradiography. J Neurochem 82: 468-481.

Picciotto MR, Kenny PJ (2013). Molecular mechanisms underlying behaviors related to nicotine addiction. Cold Spring Harb Perspect Med 3: a012112. 
Pruessner JC, Kirschbaum C, Meinlschmid G, Hellhammer DH (2003). Two formulas for computation of the area under the curve represent measures of total hormone concentration versus time-dependent change. Psychoneuroendocrinology 28: 916-931.

Rasmussen T, Swedberg MD (1998). Reinforcing effects of nicotinic compounds: intravenous self-administration in drugnaive mice. Pharmacol Biochem Behav 60: 567-573.

Rollema H, Shrikhande A, Ward KM, Tingley FD III, Coe JW, O'Neill BT et al (2010). Pre-clinical properties of the alpha4beta2 nicotinic acetylcholine receptor partial agonists varenicline, cytisine and dianicline translate to clinical efficacy for nicotine dependence. Br J Pharmacol 160: 334-345.

Salminen O, Murphy KL, McIntosh JM, Drago J, Marks MJ, Collins AC et al (2004). Subunit composition and pharmacology of two classes of striatal presynaptic nicotinic acetylcholine receptors mediating dopamine release in mice. Mol Pharmacol 65: 1526-1535.

Slemmer JE, Martin BR, Damaj MI (2000). Bupropion is a nicotinic antagonist. J Pharmacol Exp Ther 295: 321-327.

Sobieraj DM, White WB, Baker WL (2013). Cardiovascular effects of pharmacologic therapies for smoking cessation. J Am Soc Hypertens 7: 61-67.
Spiller K, Xi ZX, Li X, Ashby CR Jr., Callahan PM, Tehim A et al (2009). Varenicline attenuates nicotine-enhanced brain-stimulation reward by activation of alpha4beta2 nicotinic receptors in rats. Neuropharmacology 57: 60-66.

Stokes C, Papke RL (2012). Use of an alpha3beta4 nicotinic acetylcholine receptor subunit concatamer to characterize ganglionic receptor subtypes with specific subunit composition reveals species-specific pharmacologic properties. Neuropharmacology 63: 538-546.

Stolerman IP, Garcha HS, Pratt JA, Kumar R (1984). Role of training dose in discrimination of nicotine and related compounds by rats. Psychopharmacology (Berl) 84: 413-419.

Stolerman IP, Jarvis MJ (1995). The scientific case that nicotine is addictive. Psychopharmacology (Berl) 117: 2-10.

Toll L, Zaveri NT, Polgar WE, Jiang F, Khroyan TV, Zhou W et al (2012). AT-1001: a high affinity and selective alpha3beta4 nicotinic acetylcholine receptor antagonist blocks nicotine selfadministration in rats. Neuropsychopharmacology 37: 1367-1376.

West R, Zatonski W, Cedzynska M, Lewandowska D, Pazik J, Aveyard P et al (2011). Placebo-controlled trial of cytisine for smoking cessation. N Engl J Med 365: 1193-1200. 